\title{
特集小览脳神経外科疾患の課題と展望
}

\author{
小児水頭症に対する VP シャント術 vs. 神経内視鏡手術 \\ 一現状と課題一
}

原田 敦子

高槻病院小児脳神経外科

\section{Ventriculo-Peritoneal Shunt vs. Neuroendoscopic Surgery in Pediatric Hydrocephalus}

\author{
Atsuko Harada, M.D. \\ Department of Pediatric Neurosurgery, Takatsuki General Hospital
}

Since the introduction of neuroendoscopy to Japan in the 1990s, endoscopic diversions of the intracranial cerebrospinal pathway, such as endoscopic third ventriculostomy (ETV), have been performed. However, ventriculo-peritoneal shunt (VPS) is still the standard procedure because indications for ETV are limited. The effectiveness of ETV is believed to be considerably influenced by age, and indications for ETV in infants have been controversial. In 2016, a prospective multicenter study compared ETV and VPS in children with aqueductal stenosis aged $<2$ years. Six-month ETV success rates were found to be $59 \%$ in infants aged $<6$ months and $80 \%$ in children aged $\geq 6$ months. ETV appeared to have a higher failure than VPS in infants aged $<6$ months. However, ETV showed results equivalent to VPS in children aged $\geq 6$ months. Recent reports have indicated that the use of ETV with choroid plexus cauterization (CPC) increases its effectiveness; however, indications for $\mathrm{CPC}$ remain unclear.

The best available procedure for the treatment of pediatric hydrocephalus should be selected from a wide range of procedures such as VPS, ETV, combined use of endoscopic diversions of the intracranial cerebrospinal pathway and VPS, and combined use of ETV and CPC taking into consideration the child's condition and age.

(Received March 30, 2018; accepted May 30, 2018)

Key words : hydrocephalus, endoscopic third ventriculostomy, ventriculo-peritoneal shunt, children, choroid plexus cauterization

Jpn J Neurosurg（Tokyo）27:646-652, 2018

\section{はじめに}

1990 年代後半に神経内視鏡が導入され，水頭症に対 し，神経内視鏡下第三脳室底開空術（endoscopic third ventriculostomy：ETV）をはじめとする頭蓋内髄液短絡 術が可能となった。また，シャントデバイスの開発も進
み，抗サイフォン圧可変式バルブ，重力可変式バルブが 日常的に使わ秃るようになっている。しかし，未解決な 問題も多い.

小児水頭症に対しては，成人と異なり，成長・発達と いう観点から治療を進めていく必要がある。児の病態と 年齢を考慮して，脳室腹腔短絡術（ventriculo-peritoneal

連絡先：原田敦子， $\overline{7}$ 569-1192 高梘市古曽部町 1-3-13 高梘病院小児脳神経外科

Address reprint requests to : Atsuko Harada, M.D., Department of Pediatric Neurosurgery, Takatsuki General Hospital, 1-3-13 Kosobe-cho, Takatsuki-shi, Osaka 569-1192, Japan 
Table 1 Pediatric hydrocephalus : systemic literature review and evidence-based guidelines modified from references 1 , $4,6,10,11,17,18,20$, and 23 .

\begin{tabular}{|c|c|c|c|}
\hline & Title & Objective & Conclusions \\
\hline Part 1 & Introduction and methodology & & \\
\hline Part 2 & $\begin{array}{l}\text { Management of posthemorrhagic hydrocephalus in pre- } \\
\text { mature infants }\end{array}$ & $\begin{array}{l}\text { Reservoir, drainage, subgaleal shunt, } \\
\text { lumbar puncture } \\
\text { Thrombolytic agents (tPA or urokinase) } \\
\text { Acetazolamide, furosemide } \\
\text { ETV }\end{array}$ & $\begin{array}{l}\text { O } \\
\text { NR } \\
\text { NR } \\
\text { IE }\end{array}$ \\
\hline Part 3 & $\begin{array}{l}\text { Endoscopic computer-assisted electromagnetic naviga- } \\
\text { tion and ultrasonography as technical adjuvants for } \\
\text { shunt placement }\end{array}$ & $\begin{array}{l}\text { Endoscopy } \\
\text { Electromagnetic navigation } \\
\text { Ultrasonography }\end{array}$ & $\begin{array}{l}\mathrm{O} \\
\mathrm{O} \\
\mathrm{O}\end{array}$ \\
\hline Part 4 & $\begin{array}{l}\text { Cerebrospinal fluid shunt or endoscopic third ventricu- } \\
\text { lostomy for the treatment of hydrocephalus in children }\end{array}$ & ETV vs VPS & $\mathrm{E}$ \\
\hline Part 5 & Effect of valve type on cerebrospinal fluid shunt efficacy & Valve type & $\mathrm{E}$ \\
\hline Part 6 & $\begin{array}{l}\text { Preoperative antibiotics for shunt surgery in children } \\
\text { with hydrocephalus }\end{array}$ & Preoperative antibiotics & $\mathrm{R}$ \\
\hline Part 7 & $\begin{array}{l}\text { Antibiotic-impregnated shunt systems versus conven- } \\
\text { tional shunts in children with hydrocephalus }\end{array}$ & Antibiotic-impregnated shunt systems & $\mathrm{R}$ \\
\hline Part 8 & Management of cerebrospinal fluid shunt infection & $\begin{array}{l}\text { Shunt externalization vs complete shunt } \\
\text { removal }\end{array}$ & $\mathrm{E}$ \\
\hline Part 9 & Effect of ventricular catheter entry point and position & Anterior vs posterior horn & $\mathrm{E}$ \\
\hline Part 10 & $\begin{array}{l}\text { Change in ventricle size as a measurement of effective } \\
\text { treatment of hydrocephalus }\end{array}$ & Ventricle size & IE \\
\hline
\end{tabular}

$\mathrm{O}:$ option, $\mathrm{R}:$ recommended, $\mathrm{NR}:$ not recommended, IE $:$ insufficient evidence, $\mathrm{E}:$ equivalent, ETV $:$ endoscopic third ventriculostomy, VPS : ventriculo-peritoneal shunt

shunt：VPS), ETV, 頭蓋内髄液短絡術と VPS の併用, ETV と脈絡叢焼灼術 (choroid plexus cauterization: CPC) の併用など, 多彩な選択肢の中からその時点で最良の手 術法の選択を行わなければならない。本稿ではVPS と ETVの現状と課題を中心に小児水頭症の治療を概説す る.

\section{米国ガイドライン 2014}

小児水頭症の治療を行うにあたり，2014年に発表され た米国ガイドライン114)6)10)11)17) 20)23)を知っておく必要 がある。そのまとめを Table 1 に示す。Part 10 まで小児 水頭症の治療についてさまざまな項目を検討している が，エビデンスのある治療法として推奨された事項は, シャント感染予防としてのシャント術直前の抗生剤投 与，抗生剤が練り込まれたシャントカテーテルの使用の みであった。このことからも，小児水頭症は原疾患が多 様で, 各年齢で最善の治療方法が異なるため, エビデン スレベルの高い論文が少なく, 標準治療を定めるのは難 しいことがわかる。本邦でも日本小児神経外科学会が中 心となって, 小児水頭症のガイドライン作りの準備が行
われており，本邦での医療事情に即したガイドラインの 発表が待たれる。

\section{脳室腹腔短絡術}

ETVが行われるようになった現在も, 小児水頭症治療 においてVPSが標準治療である.VPS は確立された手術 方法ではあるが, 乳幼児の場合, シャントトラブルの発 生率が成人より高いことは周知の事実である。初回シャ ントが有効である率( shunt survival rate) は 1 年で $60 \%$, 2 年で $50 \%, 10$ 年で $30 \%$ という Sainte-Rose ら ${ }^{21)}$

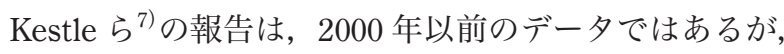
依然小児水頭症に対するシャント手術成績の基準として 用いられる。 シャントトラブルの原因としては, シャン トカテーテルの閉塞と感染が挙げられる。

閉塞を防ぐための工夫としては，内視鏡・ナビゲー ション・エコーなどを用いた正確な脳室内カテーテルの 留置や，スリット脳室予防のためのシャントバルブの圧 設定が行われる。しかしながら，先のガイドラインでも 示されたように，内視鏡・ナビゲーション・エコーを用 いた脳室カテーテル留置もオプションに過ぎず4), また, 
Table 2 Hydrocephalus Clinical Research Network protocol to reduce cerebrospinal fluid shunt infection modified from references 8 and 9 .

\begin{tabular}{l|l}
\multicolumn{1}{c|}{$\begin{array}{c}\text { Hydrocephalus Clinical Research Network protocol, } \\
\text { Kestle et al (2011) }\end{array}$} & \multicolumn{1}{|c}{$\begin{array}{c}\text { New Hydrocephalus Clinical Research Network protocol, } \\
\text { Kestle et al (2016) }\end{array}$} \\
\hline $\begin{array}{l}\text { Sign on operation room door to minimize traffic } \\
\text { Patient position of operation site away from door } \\
\text { Antibiotic received before incision (Cefazolin } 30 \mathrm{mg} / \mathrm{kg})\end{array}$ & - \\
Antibiotic received one dose postoperatively (Cefazolin 30 & Same \\
$\mathrm{mg} / \mathrm{kg}$ ) & Same \\
Hair clipped, not shaved & - \\
ChloraPrep applied to surgical field and not washed off & Same \\
Wait 3 minutes to allow ChloraPrep to dry & Same \\
Proper hand-washing technique by all team members & Hand scrub by all participants (antiseptic cream not allowed) \\
Double gloving by all team members & Same \\
Ioban use & Same \\
Vancomycin/Gentamicin infection into shunt reservoir & AICs (cranial and distal) for insertion procedures \\
& Two (cranial or distal) or both for revision procedures \\
\hline
\end{tabular}

AIC : antibiotic-impregnated shunt catheters, ChloraPrep : preoperative skin preparation products containing chlorhexidine gluconate and isopropyl alcohol, Ioban: antimicrobial incise drapes

シャントシステムの違いでシャント手術の結果に差はみ られないとされている11)。スリット脳室を予防する目的 で近年重力可変式バルブが開発されたが，こちらも従来 の報告とは変わらない結果であり占，今後も理想のシャ ントシステムの開発が待たれる。

従来 VPS の感染率は 10\%程度といわれていたが，感 染を減らす対策として, standardized protocol が 2011 年 に Kestle らにより提案された ${ }^{8)}$. 北米の 4 センターでこ のプロトコールに則って手術を行ったところ, 感染率が 8.8\%から 5.7\%に下がったと報告された。 以後このプロ トコールが現在の標準的な感染対策となってきた。 2011 年のプロトコールは 11 の項目があるためにコンプライ アンスが $74.5 \%$ と比較的悪く，また，このプロトコール が発表された後, 北米では前述の抗生剂が練り込まれた シャントカテーテルの有効性が先のガイドラインで示さ れたこともあり ${ }^{11)}$ ，抗生剂練り込みシャントカテーテル をプロトコールに取り入れることで，プロトコールを簡 略化したものが 2016 年に発表された ${ }^{9)}$ 。この新しいプロ トコールでの感染率は $6.0 \% て ゙ ， 2011$ 年のものと有意差 はなかった。 2011 年と 2016 年のプロトコールの詳細を Table 2 に示す. 日本でも抗生剤が練り込まれたシャント カテーテルの発売が 2018 年に予定されており, 国内例 でシャント感染の減少を有意差をもって証明できるか期 待される。

\section{神経内視鏡下第三脳室底開空術}

ETV の手術適応は, 原則として脳室内髄液路のどこか に閉塞機転を認め, 骾液の産生過多と吸収不全がない水 頭症病態とされる。その有効性を予測する方法として， 年齢，原疾患，シャント術の既往が議論されてきたが, ETVの成功率の予測として, 2009 年に Kulkarni ら ${ }^{12)}$ が 提唱した ETV success score (ETVSS) が重用されるよう になっている（Table 3)。これは年齢，水頭症の原因， シャント手術の既往の 3 項目の合計值から成功率を予測 するもので，ETVの手術適応を決めるものではない.

ETV の成績としては, 2007 年に Drake ${ }^{33)}$ が報告した カナダでの多施設共同研究の結果がしばしば取り上げら れる。カナダの 9 施設で 15 年間に行われた 368 例が対象 で，平均年齢 6.5 歳，原疾患は中脳水道近傍の脳腫瘍や 原発性中脳水道狭窄症などの閉塞性水頭症が $63 \%$ で あった。術後 1 年と 5 年の ETV の有効率は全体でそれぞ れ 65\%，52\%で，術後 5 年の有効率を年齢別にみると， 生後 1 力月以下が $28 \%, 6$ 力月〜 1 歳は $40 \%, 10$ 歳以上 では $68 \%$ であり, 特に乳児では有効率が低かった。合併 症は $13.6 \%$ にられ, 髄液漏 $3.6 \%$, 髄膜炎 $2.8 \%$, 出血,

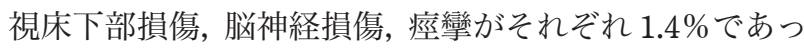
た。また，2例（1.4\%）は late rapid deterioration で死亡 していた。これは 2006 年に Drake $ら^{2)}$ が報告した開空部 の閉塞による水頭症症状の悪化が原因と考えられてい る。 シャント閉塞と同様の症状を呈し，ときに致死的と なる病態である。したがって ETV 後も VPS 後と同様, 
Table 3 Endoscopic third ventriculostomy success score (ETVSS) modified from reference 12 .

\begin{tabular}{|c|c|c|c|}
\hline Score & Age & Etiology & Previous shunt \\
\hline 0 & $<1$ month & Post-infectious & Previous shunt \\
\hline 10 & 1-6 months & & No previous shunt \\
\hline 20 & & Myelomeningocele & \\
\hline & & Intraventricular hemorrhage & \\
\hline & & Nontectal brain tumor & \\
\hline 30 & 6 months -1 year & Aqueductal stenosis & \\
\hline & & $\begin{array}{l}\text { Tectal tumor } \\
\text { Other }\end{array}$ & \\
\hline 40 & 1 year-10 years & & \\
\hline 50 & 10 years $\leqq$ & & \\
\hline
\end{tabular}

ETVSS is calculated by adding age score, etiology score, and previous shunt score.

定期的な画像による経過観察が必要である.

ETVの最新の治療成績としては，2016 年の Hydrocephalus Clinical Research Network からの報告がある ${ }^{14)}$. 336 例の小児水頭症に対する ETV の成績で, 対象の年齢 中央值は 6.9 歳，46\%が中脳水道での狭窄が原因であっ た. 30 日，90日，1年，2年後の成功率はそれぞれ $73.7 \% ，$ $66.7 \% ， 64.8 \% ， 61.7 \%$ でり，術後 1 年の成績を前述の 2007 年の Drake らの報告と比較すると同等であった。こ の報告では，ETVSS と ETVの成功率は比例しており， 他に関与する因子としては，開空後に奥の脳底動脈がよ く見えたかどうかも成功率に関与していると述べられて いる.

\section{脳室腹腔短絡術 vs. 神経内視鏡下 第三脳室底開空術}

米国ガイドライン ${ }^{17)}$ での ETV と VPS の比較では, ETV と VPS は同等の治療効果であると結論づけられて いるが，このガイドラインが発表された後，以下の $2 つ$ の多施設大規模臨床研究が発表され，適応を考慮すれば ETV のほうが VPS を上回るかもしくは同等の成功率が 得られることが示された。1つは先述した 2016 年の Hydrocephalus Clinical Research Network からの報告であ る. ETVSS が 80 以上の症例では, 術後 6 力月の成功率 が 75.9\% と高いことから, ETVが第一選択となりうるこ とが示された ${ }^{14)}$ 。もう1つは，2016 年に報告された，2 歳未満の中脳水道狭窄症を対象として ETV と VPS の成 績を比較した International Infant Hydrocephalus Study で ある ${ }^{15)}$. 術後 6 力月時点での ETV の有効率は $66 \%$, VPS の有効率は $88 \%$ で，有意にVPS が有効であった。しか しながら，生後 6 力月未満と以上の児の術後 6 力月時点

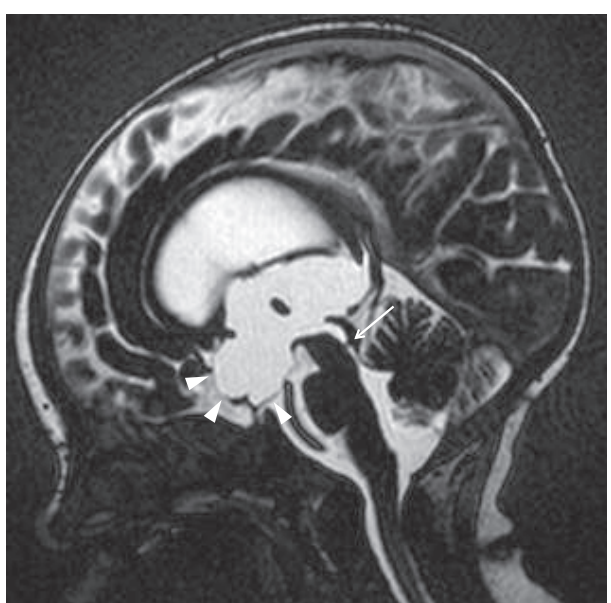

Fig. 1 T2-weighted sagittal magnetic resonance (MR) image at 1 month indicating ballooning of the third ventricle floor (arrow head) and membranous tissue in the aqueduct (arrow).

での ETVの有効率を調べてみると，それぞれ $59 \%$ と $80 \%$ で, 生後 6 力月以上では VPS とほぼ同等の有効率で あった。中脳水道狭窄症に適応を限れば，1歳以下でも ETV の適応だとする意見が以前から多かったが，この結 果から, 生後 6 力月以上の中脳水道狭窄症に対しては, VPS と ETVの成績はほとんど変わらないので，ETVが 第一選択となりうることが示された。

ここで，ETVか VPS か治療方針に悩んだ自験例を提 示する，症例は 1 力月女児で，頭囲拡大，脳室拡大を主 訴に当科初診。頭部 MRI（Fig. 1，2）で中脳水道狭窄症 による閉塞性水頭症と診断したが，頭囲拡大以外は症状 がみられないため，経過観察していた。頭囲曲線を Fig. 


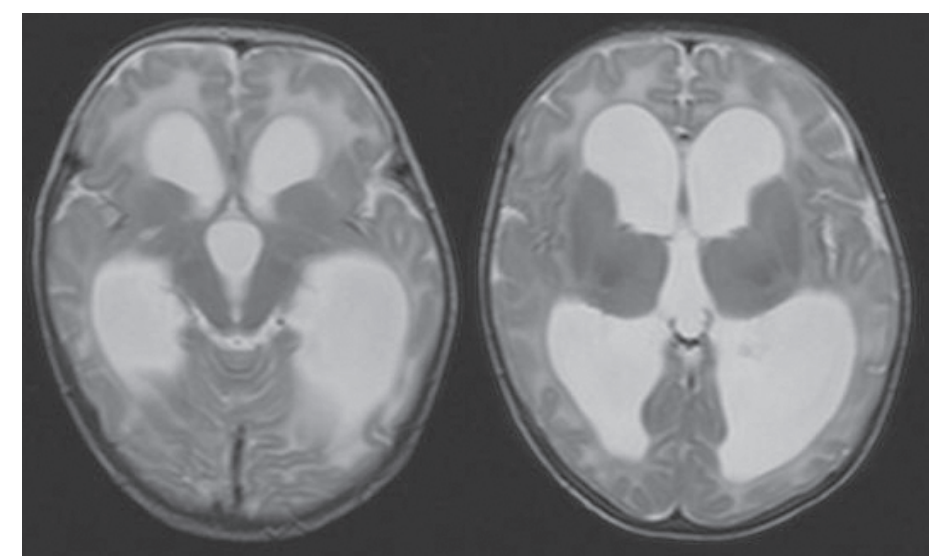

Fig. 2 T2-weighted axial MR images at 1 month showing ventriculomegaly.

3 に示す。徐々に大泉門が膨隆し, 頭囲拡大, 脳室拡大 の進行がみられたため, 5 力月時に手術を行うこととし た.この時点での ETVSS は年齢が 5 カ月なので 10 点, 病因は中脳水道狭窄症なので 30 点, 既存シャントはな いため 10 点で, 合計 50 点であった. MRI 矢状断（Fig. 1）で示したように，中脳水道に膜様物があり，第三脳室 底の ballooning も明らかな閉塞性水頭症のため, ETVか VPSか非常に敛んだが，5力月という月齢を鑑みて，VPS を選択した。術後経過は良好で, 現在発達良好（発達指 数 106）である.この症例は 2014 年の症例で，もし 2016 年の多施設共同研究 ${ }^{14)}$ の結果を踏まえて考光れば，あと 1〜2 力月手術を待って， ETV という選択肢もあったと 思われる。

\section{脈絡叢焼灼術}

$\mathrm{CPC}$ は 2005 年 $\mathrm{Warf}^{24)}$ が ETV の際に CPC を加えるこ とによって髄液産生量を減らし, ETV の成績を向上させ たという報告をして以来，注目されている術式である。 この報告での対象は 1 歳以下のアフリカの乳児で，髄膜 炎後水頭症が 58\%を占めていた。 ETVSS が 10-40の対 象であるにもかかわらず，ETV+CPC 66\%，ETV 単独で は $47 \%$ の有効率であった，Warf は ETV +CPC が奏効す る機序として, 脈絡叢での骾液産生量低下と脳室内拍動 の低下を挙げている，以後北米でも CPCが行われ，アフ リカと同様の良好な成績が報告されてきたが22，2018 年 に Hydrocephalus Clinical Research Network より ETV と $\mathrm{ETV}+\mathrm{CPC}$ の比較の論文が発表された ${ }^{16)}$. 2 歳未満の水 頭症（原疾患の内訳は脊髄髄膜瘤 $31 \%$, 脳室内出血後 $23 \%$ ，中脳水道狭窄症 $21 \%$ な゙）を対象に ETV $+\mathrm{CPC}$

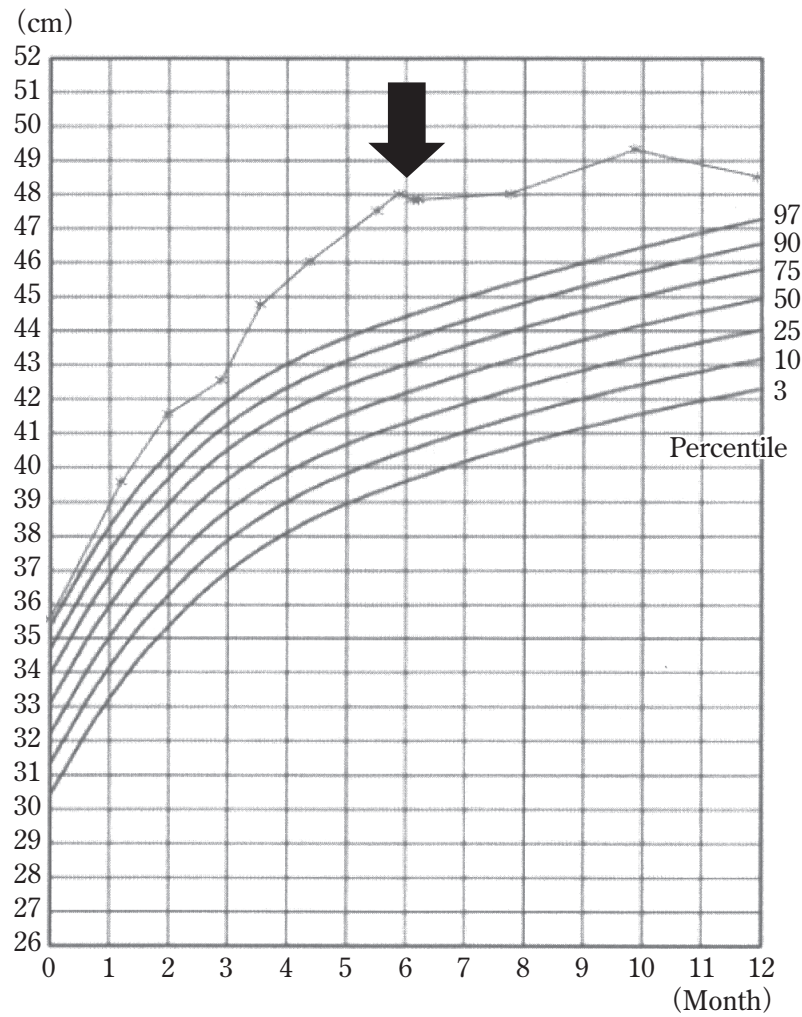

Fig. 3 Growth chart demonstrating rapid deviation of head circumference from the percentile line normally obtained. The rapid growth of the head stopped immediately after ventriculo-peritoneal shunting (arrow).

を行ったところ，6 カ月後の有効率は $36 \%$ で，有意差は ないものの, ETV 単独より低い有効率であった。この結 果から，現時点では CPC の適応は慎重にすべきであると 考えられる。 


\section{おわりに}

乳児水頭症ではVPS が標準治療であることは変わり ないが, ETVの適応も広がりつつある。合併症や再手術 のない水頭症治療を行えるように，児の原疾患や年齢， 水頭症の病態を正しく把握して最適な手術方法を選択す ることが最も重要である。

\section{謝 辞}

小児脳神経外科診療において，ご指導をいただいた故 山 崎麻美先生に感謝の意を表し，本論文を捧げます。

\section{$\mathrm{COI}$}

著者は日本脳神経外科学会への COI 自己申告の登録を完了 しています。本論文に関して開示すべき COI はありません。

\section{文 献}

1) Baird LC, Mazzola CA, Auguste KI, Klimo P Jr, Flannery AM ; Pediatric Hydrocephalus Systematic Review and Evidence-Based Guidelines Task Force : Pediatric hydrocephalus: systematic literature review and evidence-based guidelines. Part $5:$ Effect of valve type on cerebrospinal fluid shunt efficacy.J Neurosurg Pediatr 14 (suppl 1) : 3543, 2014.

2) Drake J, Chumas P, Kestle J, Pierre-Kahn A, Vinchon M, Brown J, Pollack IF, Arai H : Late rapid deterioration after endoscopic third ventriculostomy : additional cases and review of the literature. J Neurosurg 105 (2 Suppl) : 118126, 2006

3) Drake JM : Endoscopic third ventriculostomy in pediatric patients: the Canadian experience. Neurosurgery 60 : 881-886, 2007.

4) Flannery AM, Duhaime AC, Tamber MS, Kemp J; Pediatric Hydrocephalus Systematic Review and Evidence-Based Guidelines Task Force : Pediatric hydrocephalus : systematic literature review and evidence-based guidelines. Part 3 : Endoscopic computer-assisted electromagnetic navigation and ultrasonography as technical adjuvants for shunt placement. J Neurosurg Pediatrics 14 (suppl 1) : 24-29, 2014.

5）原田敦子, 西山健一, 吉村淳一, 佐野正和, 藤井幸彦： proGAV $^{\circledR}$ シャントシステムによる小児水頭症の治療成 績。小児の脳神経 38:269-275, 2013.

6) Kemp J, Flannery AM, Tamber MS, Duhaime AC; Pediatric Hydrocephalus Systematic Review and Evidence-Based Guidelines Task Force: Pediatric hydrocephalus : systematic literature review and evidence-based guidelines. Part 9 : Effect of ventricular catheter entry point and position. $J$ Neurosurg Pediatr 14 (suppl 1) : 72-76, 2014.

7) Kestle J, Drake J, Milner R, Sainte-Rose C, Cinalli G, Boop F, Piatt J, Haines S, Schiff S, Cochrane D, Steinbok P, MacNeil N : Long-term follow-up data from the shunt design trial. Pediatr Neurosurg $33:$ 230-236, 2000.

8) Kestle JR, Riva-Cambrin J, Wellons JC 3rd, Kulkarni AV, Whitehead WE, Walker ML, Oakes WJ, Drake JM, Luerssen TG, Simon TD, Holubkov R: A standardized protocol to reduce cerebrospinal fluid shunt infection : The Hydroceph- alus Clinical Research Network Quality Improvement Initiative.J Neurosurg Pediatr 8: 22-29, 2011.

9) Kestle JR, Holubkov R, Douglas Cochrane D, Kulkarni AV, Limbrick DD Jr, Luerssen TG, Jerry Oakes W, Riva-Cambrin J, Rozzelle C, Simon TD, Walker ML, Wellons JC 3rd, Browd SR, Drake JM, Shannon CN, Tamber MS, Whitehead WE ; Hydrocephalus Clinical Research Network: A new Hydrocephalus Clinical Research Network protocol to reduce cerebrospinal fluid shunt infection. J Neurosurg Pediatr 17: 391-396, 2016.

10) Klimo P Jr, Van Poppel M, Thompson CJ, Baird LC, Duhaime AC, Flannery AM ; Pediatric Hydrocephalus Systematic Review and Evidence-Based Guidelines Task Force: Pediatric hydrocephalus: systematic literature review and evidence-based guidelines. Part 6: Preoperative antibiotics for shunt surgery in children with hydrocephalus : a systematic review and meta-analysis.J Neurosurg Pediatr $\mathbf{1 4}$ (suppl) : 44-52, 2014.

11) Klimo P Jr, Thompson CJ, Baird LC, Flannery AM ; Pediatric Hydrocephalus Systematic Review and Evidence-Based Guidelines Task Force : Pediatric hydrocephalus : systematic literature review and evidence-based guidelines. Part 7: Antibiotics-impregnated shunt systems versus conventional shunts in children: a systematic review and metaanalysis. J Neurosurg Pediatr 14 (suppl) : 53-59, 2014.

12) Kulkarni AV, Drake JM, Mallucci CL, Sgouros S, Roth J, Constantini S ; Canadian Pediatric Neurosurgery Study Group : Endoscopic third ventriculostomy in the treatment of childhood hydrocephalus. J Pediatr 155: 254-259, e1, 2009.

13) Kulkarni AV, Drake JM, Kestle JR, Mallucci CL, Sgouros S, Constantini S ; Canadian Pediatric Neurosurgery Study Group : Predicting who will benefit from endoscopic third ventriculostomy compared with shunt insertion in childhood hydrocephalus using the ETV Success Score. J Neurosurg Pediatr 6:310-315, 2010.

14) Kulkarni AV, Riva-Cambrin J, Holubkov R, Browd SR, Cochrane DD, Drake JM, Limbrick DD, Rozzelle CJ, Simon TD, Tamber MS, Wellons JC 3rd, Whitehead WE, Kestle JR ; Hydrocephalus Clinical Research Network : Endoscopic third ventriculostomy in children : prospective, multicenter results from the Hydrocephalus Clinical Research Network. J Neurosurg Pediatr $18:$ 423-429, 2016.

15) Kulkarni AV, Sgouros S, Constantini S ; IIHS Investigators : International Infant Hydrocephalus Study : initial results of a prospective, multicenter comparison of endoscopic third ventriculostomy (ETV) and shunt for infant hydrocephalus. Childs Nerv Syst 32: 1039-1048, 2016.

16) Kulkarni AV, Riva-Cambrin J, Rozzelle CJ, Naftel RP, Alvey JS, Reeder RW, Holubkov R, Browd SR, Cochrane DD, Limbrick DD Jr, Simon TD, Tamber M, Wellons JC 3rd, Whitehead WE, Kestle JRW : Endoscopic third ventriculostomy and choroid plexus cauterization in infant hydrocephalus : a prospective study by the Hydrocephalus Clinical Research Network. J Neurosurg Pediatr 21 : 214-223, 2018.

17) Limbrick DD Jr, Baird LC, Klimo P Jr, Riva-Cambrin J, Flannery AM ; Pediatric Hydrocephalus Systematic Review and Evidence-Based Guidelines Task Force : Pediatric hydrocephalus: systematic literature review and evidence-based guidelines. Part 4: Cerebrospinal fluid shunt or endoscopic third ventriculostomy for the treatment of hydrocephalus in children. J Neurosurg Pediatr 14 (suppl) : 30-34, 2014.

18) Mazzola CA, Choudhri AF, Auguste KI, Limbrick DD Jr, 
Rogido M, Mitchell L, Flannery AM ; Pediatric Hydrocephalus Systematic Review and Evidence-Based Guidelines Task Force: Pediatric hydrocephalus : systemic literature review and evidence-based guidelines. Part 2: Management of posthemorrhagic hydrocephalus in premature infants. $J$ Neurosurg Pediatr 14 (suppl) : 8-23, 2014.

19）宮嶋雅一, 下地一彰, 木村孝興, 新井 一: 米国ガイド ラインに基づいた小児水頭症の標準治療一小児水頭症に 対する今日の最善の治療法は何か? 一. 脳外誌 26 ： 564-573, 2017.

20) Nikas DC, Post AF, Choudhri AF, Mazzola CA, Mitchell L, Flannery AM ; Pediatric Hydrocephalus Systematic Review and Evidence-Based Guidelines Task Force: Pediatric hydrocephalus : systematic literature review and evidencebased guidelines. Part 10: Change in ventricle size as a measurement of effective treatment of hydrocephalus. $J$ Neurosurg Pediatr 14 (suppl) : 77-81, 2014.

21) Sainte-Rose C, Piatt JH, Renier D, Pierre-Kahn A, Hirsch
JF, Hoffman HJ, Humphreys RP, Hendrick EB : Mechanical complications in shunts. Pediatr Neurosurg $17: 2^{-9}, 1991^{-}$ 1992.

22) Stone SSD, Warf BC : Combined endoscopic third ventriculostomy and choroid plexus cauterization as primary treatment for infant hydrocephalus : a prospective North American series. J Neurosurg Pediatr 14: 439-446, 2014.

23) Tamber MS, Klimo P Jr, Mazzola CA, Flannery AM ; Pediatric Hydrocephalus Systematic Review and Evidence-Based Guidelines Task Force: Pediatric hydrocephalus : systematic literature review and evidence-based guidelines. Part 8: Management of cerebrospinal shunt infection.J Neurosurg Pediatr 14 (suppl) : 60-71, 2014.

24) Warf BC : Comparison of endoscopic third ventriculostomy alone and combined with choroid plexus cauterization in infants younger than 1 year of age : a prospective study in 550 African children. J Neurosurg 103 (6 Suppl) : 475-481, 2005.

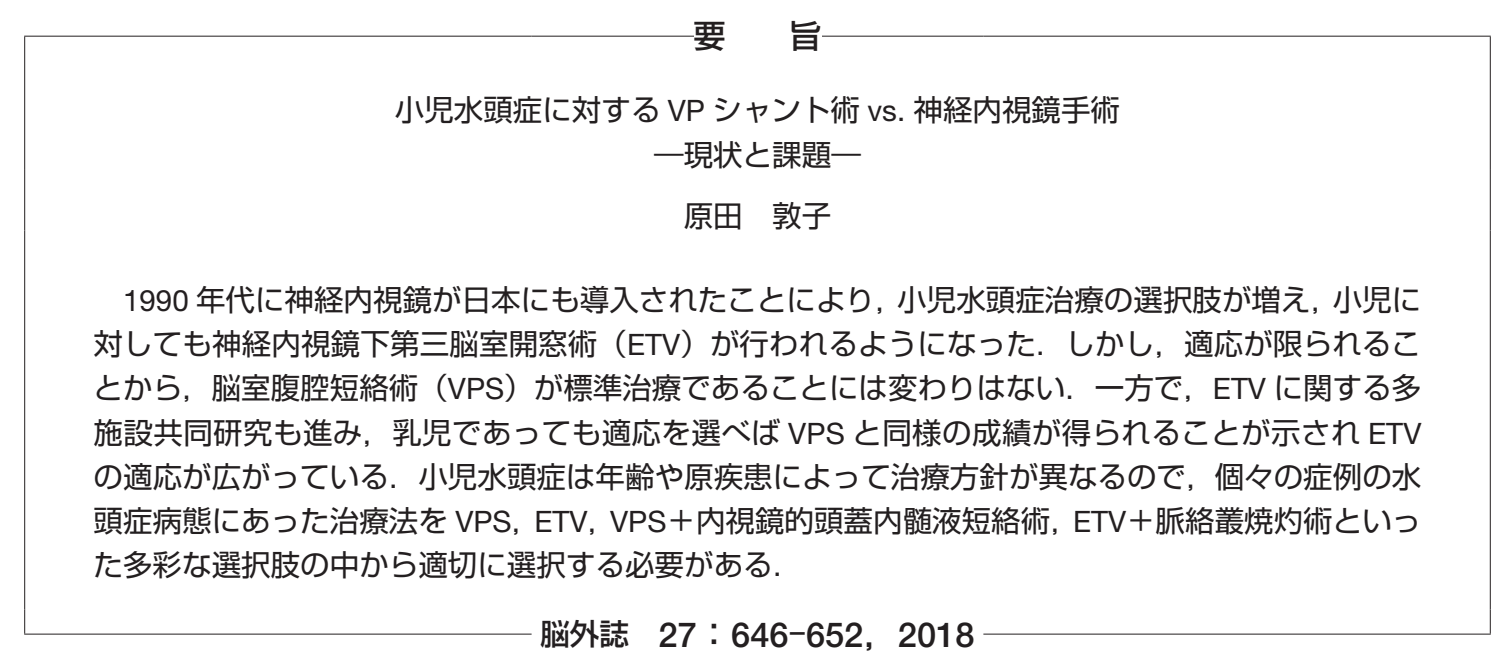

